\title{
Livelihood Expansion and Local People's Expectations in the Realm of China-Pakistan Economic Corridor in Hunza, Gilgit Baltistan, Pakistan
}

\author{
Tehzeeb Bano*1, Umer Khayyam ${ }^{1}$ and Arif Alam ${ }^{2}$
}

\begin{abstract}
:
Economic Corridors around the world has been creating livelihood opportunities for people thus stimulating economic growth and development. This study has explored the opportunities for livelihood expansion which exists in the China Pakistan Economic Corridor (CPEC) for the people of Gilgit Baltistan (GB), as the region lacks many vital livelihood opportunities. CPEC is considered as a fate changer, specifically for the people of Hunza valley, which provides the pathway to CPEC emanating from China to the rest of Pakistan. The economic growth process in the region is now been linked with the expansion of livelihood opportunities to benefit the local poor. This study has deployed quantitative research technique and used purposive sampling technique for field survey. Results show that a major bulk $-60 \%$ of the local respondents, $70 \%$ members of GBLA and $80 \%$ of the members of Chamber of Commerce in Hunza (Gilgit Baltistan) are hopeful that CPEC will create employment opportunities for local community. Due to high potential of GB in tourism sector, a high number of respondents (53\%) expected that tourism sector will develop through CPEC while $28 \%$ of the local people and the members of Chamber of Commerce expected that industrial sector will get boost through CPEC, $19 \%$ of the respondents were having opinion that agriculture sector will develop through this mega project creating employment opportunities for the local youth in their native area.
\end{abstract}

Keywords: CPEC, Gilgit Baltistan, employment opportunities, tourism, small industries.

\section{Introduction}

Economic corridors are the developmental projects that support a country to expand its internal or local economic activities [De and Iyengar (2014], through establishing connections between different economic hubs, establishing interconnectivity in transport networks and boosting technologies, which are essential for regional economic and trade integration [Brunner (2013].

Developing economic corridors has become a new phenomenon in Asia, with the aim to develop regional cooperation among different countries. In the Asian continent, this concept has first taken place in the South-East Asian region [Wolf (2016)]. Most of the modern industrialized nations have placed economic corridors at the centre of their socioeconomic and national developmental plans, e.g., numerous universal economic organizations are employing economic corridors as the essential policy to backup local development agenda [Nogales (2014)]. Selecting a suitable geographic region with enough

|*Corresponding author.

${ }^{1}$ Development Studies Department, School of Social Sciences \& Humanities (S3H), National University of Science \& Technology (NUST), H-12 Islamabad 44000, Pakistan.

${ }^{2}$ COMSATS University Islamabad, Abbottabad Campus 22060. 
economic potential and volume is important for the implementation of economic corridors around the world [Thomas (2009)]. It is being practised by many nation-states around the world to frame significant plans for sustainable development. Among those plans developing corridors is one of the major activities [Litman (2002)]. In order to further enhance such plans, the non-economic components like health, education, culture, and atmosphere are also being improved through the economic activities, like in many African nations, the programs are underway to convert the present halls of development into economic corridors. It is to meet the local needs of food security, agricultural growth, and trade corporations [Nogales (2014)]. Thus, developing economic corridors in today's contemporary world is considered as an important tool to boost developmental plans, also to enable employment as it is considered to be significant for intensifying economic ties and regional integration [Butt and Butt (2015)]. It is behind the fact that economic corridors and road linkages provide better opportunities for small towns and areas which is having stagnated economic activities as well as it enhances businesses [Hauptfleisch and Marx (2011)].

Economic corridors are more specifically linked to the expansion of the transportation industry, as it improves accessibility and convenience. It also brings investment and employment opportunities in trade and business in the isolated and remote regions. Transport development provides easy access to goods and services, costs of shipping and transport reduced through proper and timely delivery [Mohmand et al., (2016)]. Thus, for the economic development of an underdeveloped area, it is necessary to improve the internal accessibility and mobility through the expansion of road networks and upgraded transportation [Taaffe et al., (1963)].

Furthermore, improvement and expansion of the infrastructure corridors are closely linked with the expansion of the tourism industry and creation of rural-based tourism opportunities for the local residents [Rogerson (2001)]. Henceforth, the basic necessities of life should be addressed through this economic corridor and it should also contributes to livelihood safety and provides opportunities in tourism sector [Anand (2015)]. Evidence shows that the development of economic corridors opens up opportunities in small and medium enterprises, as well as in the tourism sector [Rogerson (2002)]. Although the development of tourism has negative ecological and environmental impacts in the region such as pollution and waste generation, on the other hand, it also poses positive impacts on the society [Mbaiwa (2003)].

\section{CPEC Background}

China and Pakistan have continued their friendly ties with each other; together both countries are handling with the challenges of the international world and had celebrated their 55 years of friendship and political ties in 2006 [Azeemi (2007)]. China Pakistan economic corridor is part of the Chinese policy of 'One Belt One Road (OBOR)' and it is called as a milestone, Game Change, lifeline and monument of the era [Johnson 2016)]. China Pakistan Economic Corridor-CPEC is a project between China and Pakistan with the initial investment of $\$ 46$ billion by the Chinese government for development projects in Pakistan [Ibrar et al., (2016)]. Under this huge consortium of the mega project, CPEC contains a $3000 \mathrm{~km}$ network of roads, railway lines, energy pipelines, and fibre optic 
cables that will connect Kashgar in China's Xinjiang province with Gwadar, in Pakistan's Baluchistan province [Saeed (2016)]. CPEC policies are perceived to have, overall, positive impacts on economic and social strings of society on one hand and anticipated encouraging positive impacts to the residence of that area, on the other hand [Black (1996)].

$\mathrm{CPEC}$ is thus a window of prospect for the people of Pakistan, its investment in industrial and other related sectors have a key role in the development of the country [Hamid and Hayat (2012)]. That is why, both China and Pakistan have been making intensive efforts to revive the important Silk Road, aimed at achieving economic objectives, which will provide easy access to the people and changes their economic status through the opportunities they will avail from this project [Massarrat et al., (2015)]. It is because China Pakistan Economic Corridor not only aims at improving the transportation and communication sector but it is meant to eradicate poverty from this region and to lead the country towards economic progress [Noor (2016)]. It is further expected that the implementation of this project ${ }^{1}$ would open up a new era of industrial and socio-economic development in Pakistan [Shaikh et al., (2016)].

CPEC will open a chance for trade, predominantly in Gilgit-Baltistan region of Pakistan. Gilgit-Baltistan (GB) has a great prospects for enhancement through trade connections with China and it has the potential and conducive environment to further enhance its potentials in energy, business, fruit handling and livestock sectors [Khan (2013)]. It is perceived that this multi-billion dollars' joint venture project passing through the mighty Karakorum and Himalayas in Northern Pakistan will not only help in boosting the trade and industrial activity in GB, but it will also help in boosting tourism in the region, in general, and in Pakistan, in particular [Rana (2016)]. As one of the major aims of CPEC is to improve socio-economic situations of deprived regions of Pakistan, so the development of GB along the Karakorum Highway $(\mathrm{KKH})$ will remain as the main focus of CPEC projects. Hence, improvement of the socio-economic circumstances will positively influence peace, harmony, and reconciliation in Gilgit-Baltistan [Wolf (2016)].

\subsection{Opportunities in CPEC Project for Gilgit-Baltistan}

The construction of China Pakistan Economic corridor will be a revival and extension of the KKH (Karakoram Highway) [Sial (2014)]. CPEC will open a chance for trade, predominantly the backward province of Gilgit-Baltistan has a great chance which has previously trade connections with China and it can further enhance its potentials in different sectors like food processing [Khan (2013)]. The projects approved under CPEC for GB includes construction of the Ghizer-Chitral-Chakdara road, at the cost of 22 billion rupees, reparation and expansion of the KKH between Raikot (Diamer) and Dassu (Kohistan), and accomplishment of the on-going Thakot - Havelian bypass road which will not only boost trade but it will also bring great development in tourism sector especially in the GB province [Rana (2016)].

An expressway costing Rs. 50 billion from Gilgit to Skardu will facilitate people of GB and another from Islamabad to GB needing capital injection of Rs. 82 billion will be

1 (term) Projects is taken here in an abstract form, which represents CPEC projects or One Belt-One Road. 
constructed under the CPEC, the proposed Shonter-Astore road will reduce the distance between Azad Jammu and Kashmir (AJK) and GB by several hundred kilometres and also cut travel time between the two regions [GoP (2018)]. The business community of GB hopes that this project will increase collaboration in agriculture sector through the transfer of modern tools and machinery for the purpose of agriculture [Khan et al., (2016)]. In Gilgit- Baltistan, one special economic zone will be constructed over 250 acres' land in Maqpoondaas where Agro-based, minerals, livestock, handicrafts, and wood-related trades have been marked as potential industries. The zone will open new opportunities for businessmen and local investors and the local business communities to tap on the benefits attached to it in terms of tax holiday for a period of ten years, exemption in custom duties on imports of capital goods besides other infrastructure facilities to be guaranteed by the federal government under this project [Neelum (2017)].

Gilgit-Baltistan under CPEC grand projects will receive, Marble/Granite, Iron Ore Processing, Fruit Processing, Steel Industry, Mineral Processing Unit, Leather Industry etc. it will be established and enhanced to improve the livelihoods of the local people by creating job opportunities [GoP (2017)]. CPEC can serve as a catalyst for the much needed institutional developments in this region. The infrastructure development along with the institutional arrangements will bring this area in a better state to address the economic miseries of the communities. Improved connectivity under CPEC will provide incentives to create a strong local economy leading to a resilient rural development in Gilgit-Baltistan [Neelum (2017)]. The Pakistan-China Fibre Optic Project is one of the most significant projects in Pakistan. The $840 \mathrm{~km}$ long project is likely to be completed by 2018 with an amount of US \$44 million through Karimabad, Gilgit, Babusar, Naran, Mansehra, and Jarkyas to Rawalpindi/Islamabad. The territory of Gilgit will benefit from it. Out of 840 $\mathrm{km}$ long optic fibre cable line, $466 \mathrm{~km}$ will pass through areas of Gilgit-Baltistan. It will, apart from providing secure voice traffic, also generate employment opportunities in areas of Gilgit- Baltistan [Shafique and Iftikhar (2017)].

\subsection{Theoretical Background - Social Change Theory}

In the $19^{\text {th }}$ century, the sociologists observed that societies were progressing to higher and higher levels, applying for the Charles Darwin work in the theories of social change they found that there were changes in society's living patterns due to several factors for example diffusion of technology [Bar-On et al., (2004)]. Social Change refers to the alterations which occur in life patterns of people. It happens on the grounds that all social orders are in a consistent condition of disequilibrium [Greenwood and Guner (2008)]. Spencer and Durkheim utilized the idea of structural differentiation to demonstrate that as society develops more functions, it becomes more intricate and complex. This viewpoint has been expounded all the more as of late by Talcott Parsons [Corning (1982)]. The basic idea behind this theory is that within the past 200 years, all nations of the world have been experiencing extraordinary changes and in some societies, there are significant economic and social transformations [Trimble (2003)].

Within the term of social change theory, it is found that changes come in society due to several factors and one of the factors is successful developmental plans as people are able to target different livelihood means [Lewin (1947)]. The early theorists trusted that human 
social orders and societies advance in a unilineal way-that is improvement and development that proceeds and continues in every society. They believed that social change meant progress toward something better. They considered a change to be positive and advantageous, in light of the fact that the developmental procedure suggested that social orders would essentially achieve new and higher levels of advancement [Greenwood and Guner (2008)]. And one of the ways to achieve new and higher levels of advancement is via diffusion. Diffusion is the spreading of thoughts and ideas to different societies. This would include exchanging, trading, movement, and mass communication. International shifts in economic or political advantage also have great impacts on social change. For instance, 'Globalization' is the factor in our advanced society influencing the worldwide economy, political structures and elements like poverty, environment, gender and so on. [Quijano (2007)].

Social change theory is relevant to this study as the study focus on the grand development project of China Pakistan economic corridor and changes that are connected with people's lives. Due to the creation of multiple livelihood opportunities via CPEC in their native region, the local people of $\mathrm{GB}$ will be having a change in their lives. As Gilgit-Baltistan is a gateway to CPEC and there are grand projects for the people of GB, e.g., grand infrastructure development projects and industrial development, etc. which will give a great chance to the local people to improve their lives and make a positive change in their living patterns. Diffusion of technology and knowledge via this corridor will bring a social change in the remote areas of Gilgit-Baltistan. Due to the availability of multiple livelihood opportunities in their own area the local people can transform their lives in a better form.

\section{Problem Statement}

CPEC is passing through Gilgit-Baltistan (GB), which is an economically underdeveloped region as compared to other areas of Pakistan. GB is deprived of all fundamental socio-economic services [Sial (2014)]. Gilgit-Baltistan is one of the isolated and remote areas of Pakistan, having restricted opportunities due to its physical geography [Hussain (2017)]. This region lacks employment opportunities, health and educational services and an easy access to central and international markets, hence the youth of this area is worried about their future [Bansal (2007)]. It is due to that fact that half of the population of GB live below the poverty line. Besides this, the literacy-rate is also low and there exist limited employment opportunities in the region [Butt and Siddiqi (2015)]. Due to the remoteness of the area and lack of employment and business opportunities in GB, a number of local people move to the other cities of Pakistan for the sake of better livelihood opportunities [Dinaret et al., (2015)].

Thus, on one hand, it seems that CPEC is an indicator of development and on the other hand so many local people of GB seem hopeless and fearful thinking about this project, whether it will benefit them directly through development of small, medium and large industries. And whether, it will boost employment opportunities in the tourism sector the back of the local economy and contribute to raising the living standard of the local population through an increase in their income level. In this scenario, this study has tried to identify the anticipated impacts of CPEC form the local people's perspective. 


\subsection{Research Objectives and Research questions}

1. To identify the employment opportunities for local people of GB through CPEC.

2. To study how local people perceive the effects of CPEC project on their livelihood expansion.

This research, therefore, seeks to focus on the following research questions:

1) Does CPEC develop different sectors in the study area?

2) Does CPEC boost tourism and small industries in the region?

3) Does CPEC create employment opportunities for livelihood expansion?

\subsection{Significance of the Study}

This study is significant because such kind of study is not conducted in the study area before; this research study had tried to identify the livelihood opportunities, as a result of megaprojects, for the local people of GB. This study, therefore, has tried to dismantle the myth that CPEC will benefit only China, whereas Pakistan will serve as a trade route for Chinese goods, floating on the street of Pakistan. The findings of the study give the educators, policymakers and non-governmental and civil society organizations the concrete evidence that CPEC is duly welcomed by the local population and it will benefit local economic growth, at-least as anticipated locally.

\subsection{Data Collection and Analysis}

Both qualitative and quantitative data were used in this study through primary and secondary sources. The qualitative data was collected through secondary sources by reviewing existing literature, research papers, articles and reports sorting out the important information. These approaches are commonly used in the researches of social sciences (Malik \& Kumar, 2012). Primary data was collected through open and close-ended questionnaires based on 3-point-Likert scale. This research study has deployed the purposive sampling technique and filled out, in-total, 237 questionnaires (after excluding in-completed/un-clear/double ticked questionnaires, 13 in total) from the study area. The questionnaires had 3-point-Likert scale i.e., agree, neutral and disagree. This technique is deployed as it helps in bringing proper and detailed information about the subject matter in social-science research. It also has the quality of avoiding distraction to other themes in an area, which is not the main aim of this research. It further ensures to record accurate answers from the respondents about the highlighted problem [Kerlinger (1973)]. Other than a questionnaire survey, this research study is followed by focus group discussions and field observations, which are then interlinked with the main and sub-themes of the study. Observation tool used for this was done during the field survey by observing the actual situation of the area carefully. This is a commonly used and well-known method of social sciences for collecting data without directly engaging respondents in the data collection method (Peterson, 2013). The study targeted a wide range of respondents:

\section{General Public.}

2. Members of GB Legislative Assembly (GBLA) and GB-Council (GBC).

3. Members of Chamber of Commerce of $G B$. 
Table 1: Categories of Sample Respondents

\begin{tabular}{ll|l|l}
\hline \hline Categories of Respondents & Gender & Frequency & Percentage \\
\hline 1. General Public & Male & 164 & 69.19 \\
\cline { 2 - 4 } & Female & 42 & 17.72 \\
\hline 2. Members of GBLA/ GBC & Male & 11 & 4.64 \\
\cline { 2 - 4 } & Female & 4 & 1.68 \\
\hline 3. Members of Chamber of Commerce & Male & 15 & 6.35 \\
\cline { 2 - 4 } & Female & 1 & 0.42 \\
\hline \hline
\end{tabular}

Table 2: Age-wise Distribution of the Respondents

\begin{tabular}{l|ll|ll}
\hline \hline Demographic Variable & Male Percentage & \multicolumn{2}{|l}{ Female Percentage } \\
\hline \multirow{5}{*}{ Age } & 20 and below & 20 & 20 and below & 00 \\
& 21 to 30 & 36 & 21 to 30 & 14 \\
& 31 to 40 & 17 & 31 to 40 & 03 \\
& 41 to 50 & 00 & 41 to 50 & 02 \\
& above 50 & 02 & above 50 & 01 \\
\hline Total number $(\%)$ & & & & \\
\hline \hline
\end{tabular}

The above table shows that majority of the respondents participated in this study ranges from the age of 21 to 30 years, with the percentage of 50, the table also indicates that over $88 \%$ of the respondent is graduate and above. Keeping in view the high number of the educated respondent, it is clearly arguing that this study is educated youth-centric. Due to a high number of youth respondent, the ratio of student is also high. However, by occupation, a significant number of respondents belong to the business community. The data also presents that a good number of respondents are students or recently graduated with off-farm income range RS. $0-30000$. The above depicts that by occupation $26 \%$ are businessmen, $25 \%$ respondents are from tourism sector, $21 \%$ are students, $12 \%$ are teachers, $12 \%$ are unemployed and $04 \%$ are bankers. As the study area (Hunza) is tourism and business hub of Gilgit-Baltistan thus a large number of residents from this area directly or indirectly involves either in business or work in tourism sector, hence focusing on the objectives of the study a satisfactory number of respondents were targeted from these sectors.

Keeping in view the high number of the educated respondent, it is clearly arguing that this study is educated youth-centric. Due to a high number of youth respondent, the ratio of the student is also high. However, by occupation, a significant number of respondents belong to the business community. The data also presents that a good number of respondents are students or recently graduated with off-farm income range Rs. 0-30000.

The above depicts that by occupation $26 \%$ are businessmen, $25 \%$ of respondents are from the tourism sector, $21 \%$ are students, $12 \%$ are teachers, $12 \%$ are unemployed and $04 \%$ are bankers. As the study area (Hunza) is tourism and business hub of Gilgit-Baltistan thus a 
large number of residents from this area directly or indirectly involves either in business or work in the tourism sector, hence focusing on the objectives of the study a satisfactory number of respondents were targeted from these sectors.

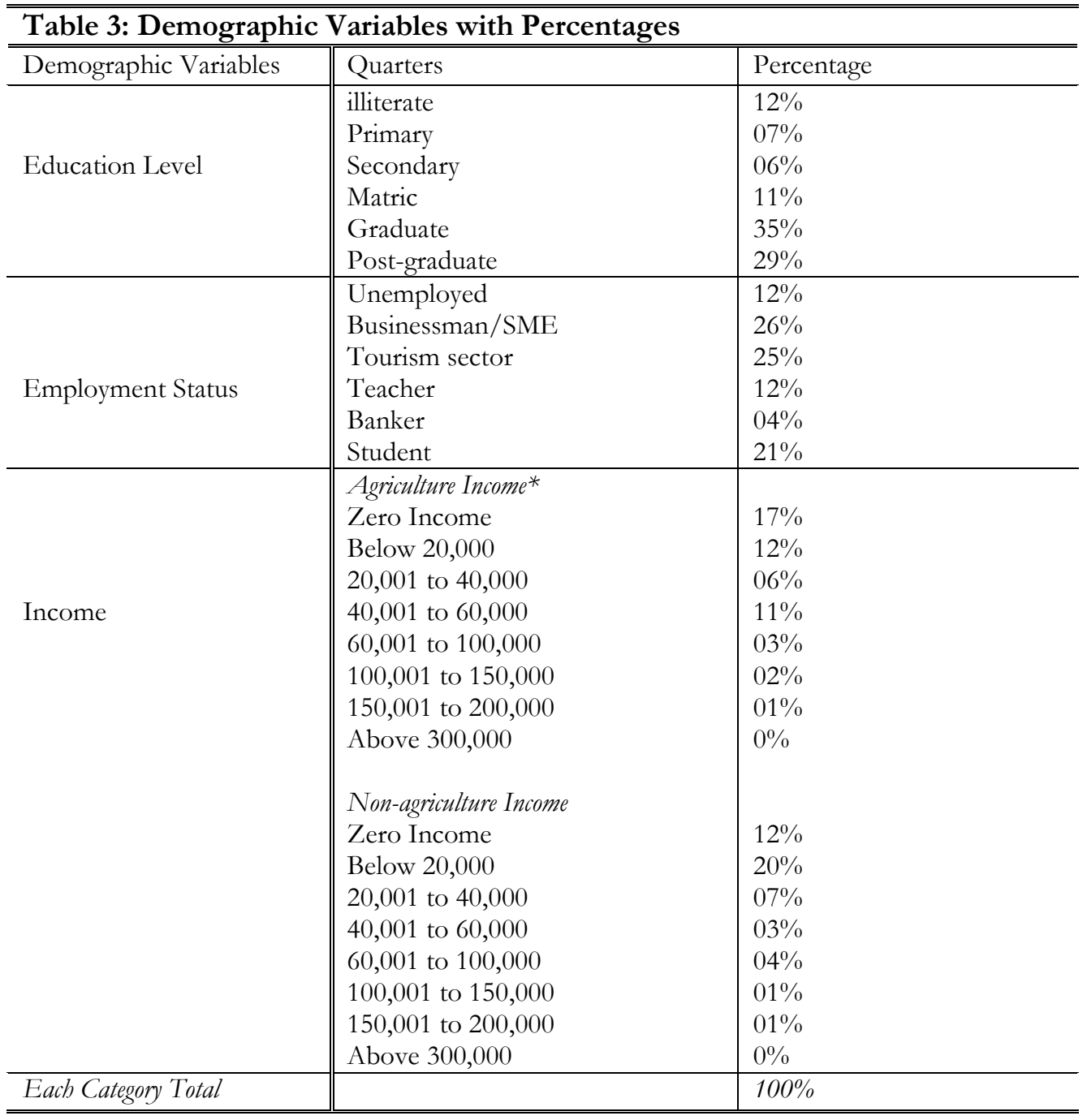

The quantitative data gathered from questionnaires were analyzed and presented as descriptive statistics i.e., percentages and averages, comparing the linked variables in the group form. Qualitative data was collected from the politicians, members of the chamber of commerce and local people from Hunza in Gilgit-Baltistan through face to face interviews and focus group discussions. Qualitative data was also analyzed by sorting the views of different respondents, compared and contrasted different opinions. Personal data and demographic information collected from the local people and from the politicians positioned an important place in the study. Understanding the importance of protection 
of personal information of the respondents will only use for legitimate purposes.

\section{Study Area And Population}

Hunza valley is a district in the mountainous area of Gilgit-Baltistan (GB) region of Pakistan, which is situated in the extreme northern part of Pakistan having borders with the Wakhan Corridor of Afghanistan and the Xinjiang region of China. Geographically, the size of the study area i.e., Hunza is $11,695 \mathrm{~km}^{2}$ with the permanent settlements of approx. 28,000 individuals and population density of 2.3 inhabitants $/ \mathrm{km}^{2}$ [GoP (1984)]. Thus, Hunza valley is the gateway of Chinese imports and is one of the hosts of mega projects to Pakistan under CPEC [DAWN (2016)]. Thus, Hunza in GB lies at the axis of Asia that gives China a way to Suez waterway and Strait of Hormuz [Sering (2012)].

Figure 1: Map of Gilgit Baltistan and Hunza valley

Source:

AKRSP.org.pk

\section{Results \& Discussion}

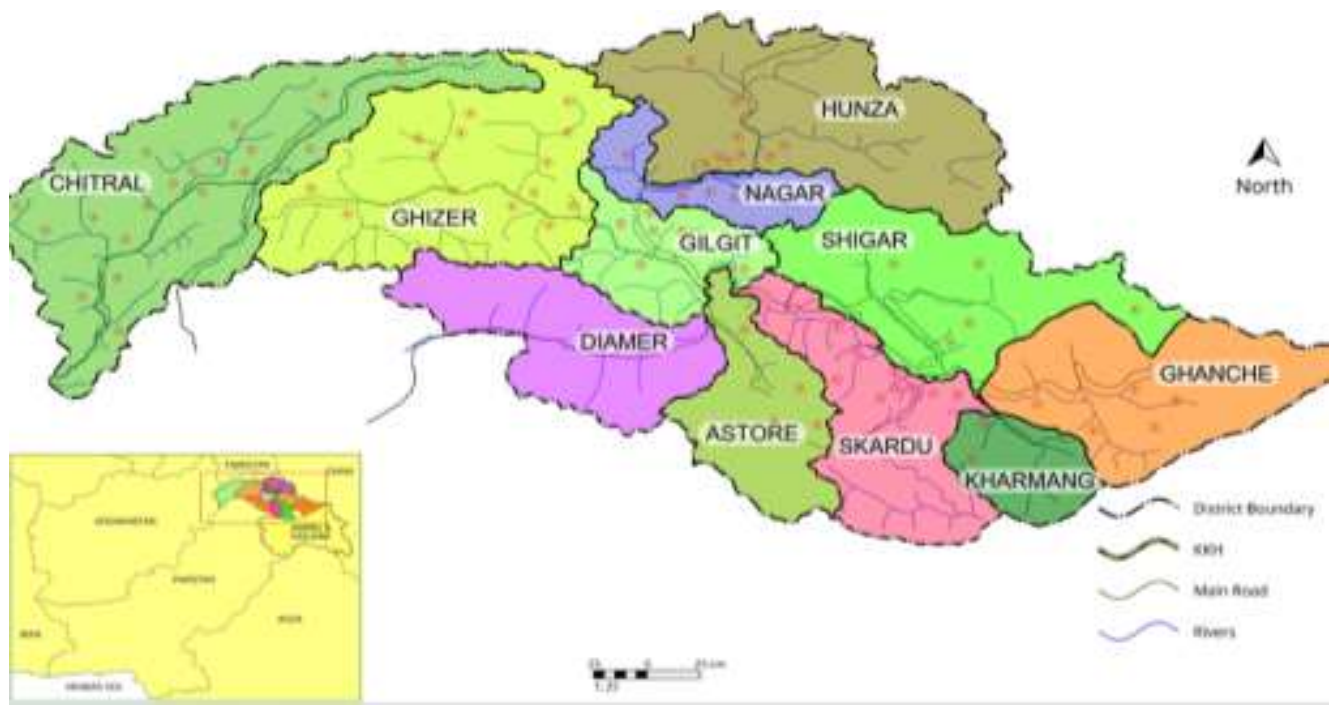

The results reveal that the major bulk of the people of Gilgit-Baltistan $(53 \%)$ are optimistic and expect that tourism sector of Gilgit-Baltistan will develop through CPEC. $28 \%$ of respondents expect that the industrial sector will develop through this project. $19 \%$ of the population from the study area expect that agriculture sector of this area will develop after this trade route starts working. However, some of the respondents were hopeless and complaining to the government for its biased attitude towards the people of Gilgit-Baltistan (See fig. 2). It is further found that $65 \%$ of the population expect that through CPEC tourism business will benefit the most, $27 \%$ respondents are optimistic and believe that the small and large industrialists will benefit the most from CPEC project. While $8 \%$ of the respondents expect that farmers from the agriculture sector will get more benefit from the CPEC project (See fig. 3). 
Figure 4 is representing the responses of local people, members of GBLA/GB Council and members of chambers of commerce against the statement about the creation of employment opportunities through CPEC. Among the local people, $60 \%$ of the respondents were found hopeful about the creation of jobs in GB through the project named as CPEC. However, $40 \%$ think that CPEC will not benefit GB in creating job and livelihood opportunities. It is also derived from the research that $70 \%$ members of GBLA and GB Council are highly relating CPEC with the creation of employment opportunities in GB, but 30\% highly educated members do not agree on the statement ' $\mathrm{CPEC}$ will create employment opportunities in GB'. The business community of GB i.e., the Chamber of Commerce were having reservations about CPEC and its functioning in GB, they were not clear about the economic zones and type of industries to be run once this project starts functioning. They were also having fear of tackling business in GB by large investors of other provinces.

During the interview one of the members of Chamber of Commerce said:

"Chamber of Commerce of Gilgit-Baltistan is demanding Economic zones in Gilgit-Baltistan. If they do not make economic zones in $G B$ then it will affect the already running business of $G B$, and we will only left seeing containers coming from China and moving towards Gawadar".

In spite of having fears, major respondents of the Chamber of Commerce with $80 \%$ are hopeful that CPEC will directly or indirectly create employment opportunities in GB however $20 \%$ of the members of Chamber of Commerce think that CPEC will not create employment opportunities in GB (See fig. 4).

It is projected that CPEC project will create 700,000 direct jobs during the period of 20152030 and it will benefit all the provinces especially the remote areas and add up in the growth of the country [Ashraf (2017)]. 60\% of the local people from the study area were also found hopeful about the creation of jobs in GB. Similarly, it is projected that, every year more than 1000 jobs will be created through CPEC energy sector which will help increase household income, likewise the tourism industry sustained to make a real modification to the lives of millions of people through creating jobs, decreasing poverty and fostering growth and development [Express Tribune (2018)]. Through the improvement of road infrastructure by CPEC, the local businessmen of GB will get a chance to double their sales by saving transport cost [Ashraf (2017)]. However, some of the respondents were hopeless and complaining to the government about its biased attitude towards the people of Gilgit-Baltistan. One of the senior members of Chamber of Commerce of GB said:

"From the day first GB is being neglected in all sectors, complete biased attitude towards its citizens from the state of Pakistan. But the state itself enjoys the tourism revenue of GB". 


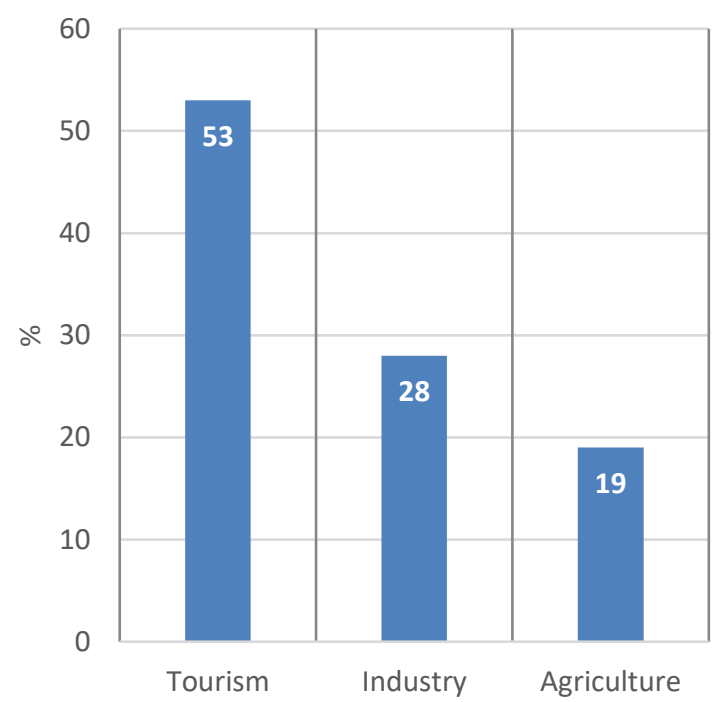

Figure 2: Sectors that will develop through CPEC?



Figure 3: Who will benefit the most from CPEC? 


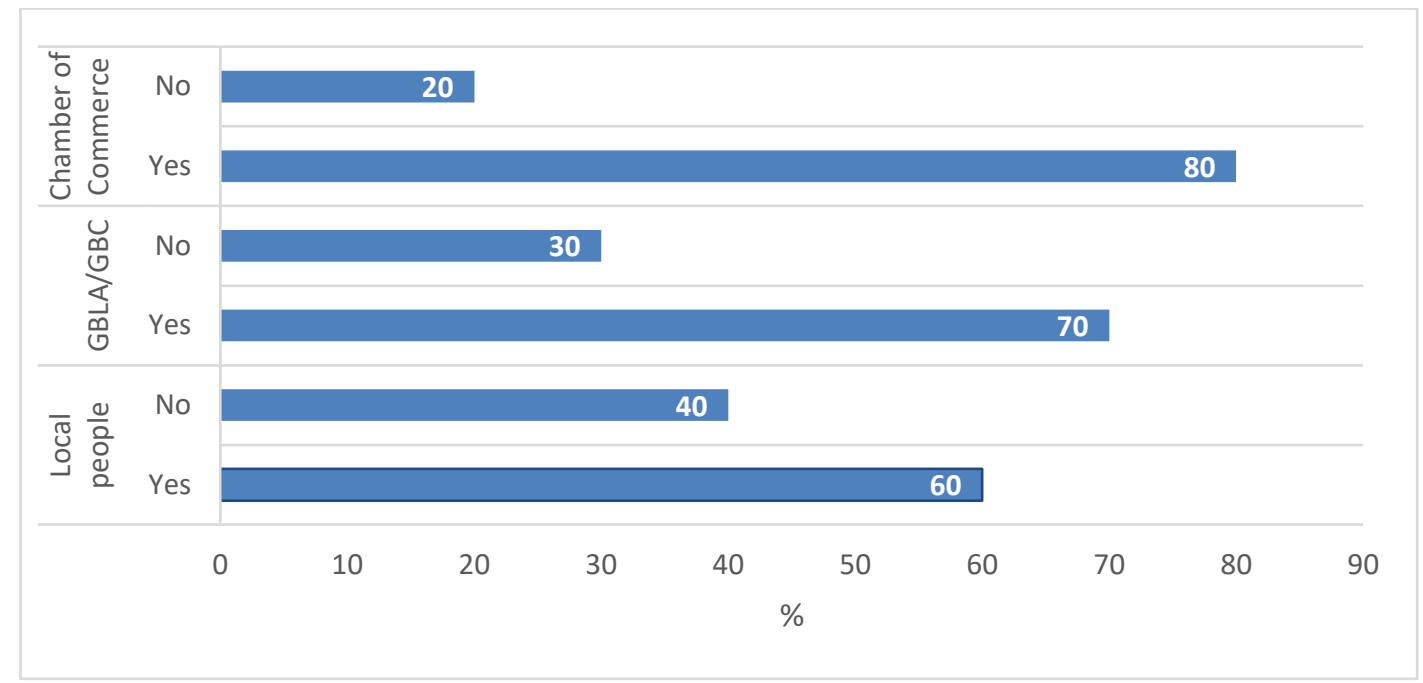

Figure 4: CPEC and Employment Opportunities in Hunza Valley

A question asked with the respondents 'Does small and medium enterprise activity such as hotels restaurants and handicraft will get boosted after this trade route starts functioning?' was positively answered and agreed by $63 \%$ respondents while $2 \%$ disagreed on it and 35\% remained neutral. However, a fair number (66\%) agreed that CPEC will benefit large businessmen of Gilgit-Baltistan. This might be due to the fact that they consider CPEC a grand project to benefit the large businessmen more than the new ones, as they are already doing business at a massive level and the project will further improve their business due to improved transportation and easy access. While 19\% were not sure about the benefits and 15\% disagreed that CPEC will benefit the large businessmen of GB (See fig. 5).

It is further found from the study that $76 \%$ respondents were agreed that CPEC will set a new era of bright future in GB, similar to the theorists of social change who believed that developmental procedure would be advantageous and it would essentially achieve new and higher levels of advancement, bringing a positive change in most of the cases [Greenwood and Guner (2008)], while 6\% respondents negated this statement and 18\% respondents were neural in response to this statement. It is followed by another $70 \%$ of the population, who were optimistic that CPEC will provide a new market for local products. While $23 \%$ from the respondents remained neutral and $7 \%$ of the population disagreed that this trade route will provide a new market for local products (See fig. 6).

The findings of the study regarding tourism reveal that the respondents seemed very much optimistic about the questions asked on tourism. A major bulk of respondents, $61 \%$ of respondents agreed that those who are already employed in the tourism sector will get more benefit from this project. $18 \%$ of respondents disagreed and the remaining $21 \%$ of respondents remained neutral. Information acquired from the study areas shows that $67 \%$ of respondents agreed and anticipated that the CPEC has an important role to play in creating employment opportunities in tourist areas. While $16 \%$ of respondents disagreed 
and $17 \%$ of the respondents remained neutral. The findings further show that $65 \%$ of the population agreed that the tourism sector of this region will get a revival after this corridor starts functioning. $20 \%$ of the population remained neutral and $15 \%$ of the population disagreed (See fig. 7).

The result shows that most of the respondents were optimistic and are relating CPEC with economic growth and reduction of poverty and raise in living standard. $61 \%$ of the respondents agreed that the living standard of the local people will increase after this trade route starts functioning while $14 \%$ do not agree and $25 \%$ remained neutral.

A local politician responded as:

"In the black and white paper generated by the government we are only having fibre optic networks and nothing else, but we do not need these 3G's and 4G's services we need projects which will helpful for the expansion of our livelihood, we need basic necessities of life".

Further, the findings have shown that 56\% respondents agreed that this project will decrease poverty in this region (Hunza) and hoping that this project will set a new era of economic progress and bright future bringing positive change in people's lives. It is comparable to the findings of the social change theory, that changes come in society due to several factors and one of the factors is successful developmental plans as people are able to target different livelihood means which decreases poverty from the society [Lewin (1947)]. 9\% of respondents were not agreed while $35 \%$ of the respondents remained neutral. Most of the respondents who were the members of Chamber of the Commerce of GB were associating bright future with the upcoming opportunities and there will be livelihood expansion. For them, CPEC is having an important role in promoting local businesses and trades which make local businessmen compete with the national and international markets and will ultimately bring improvement in the businesses. The results reveal that $64 \%$ of the population agreed that CPEC will enhance employment opportunities that will raise the household income, while 11\% from the population disagreed and $25 \%$ of the respondents remained neutral (See fig. 8). 




Figure 5: SME and Large Industries under CPEC und Hunza V alley

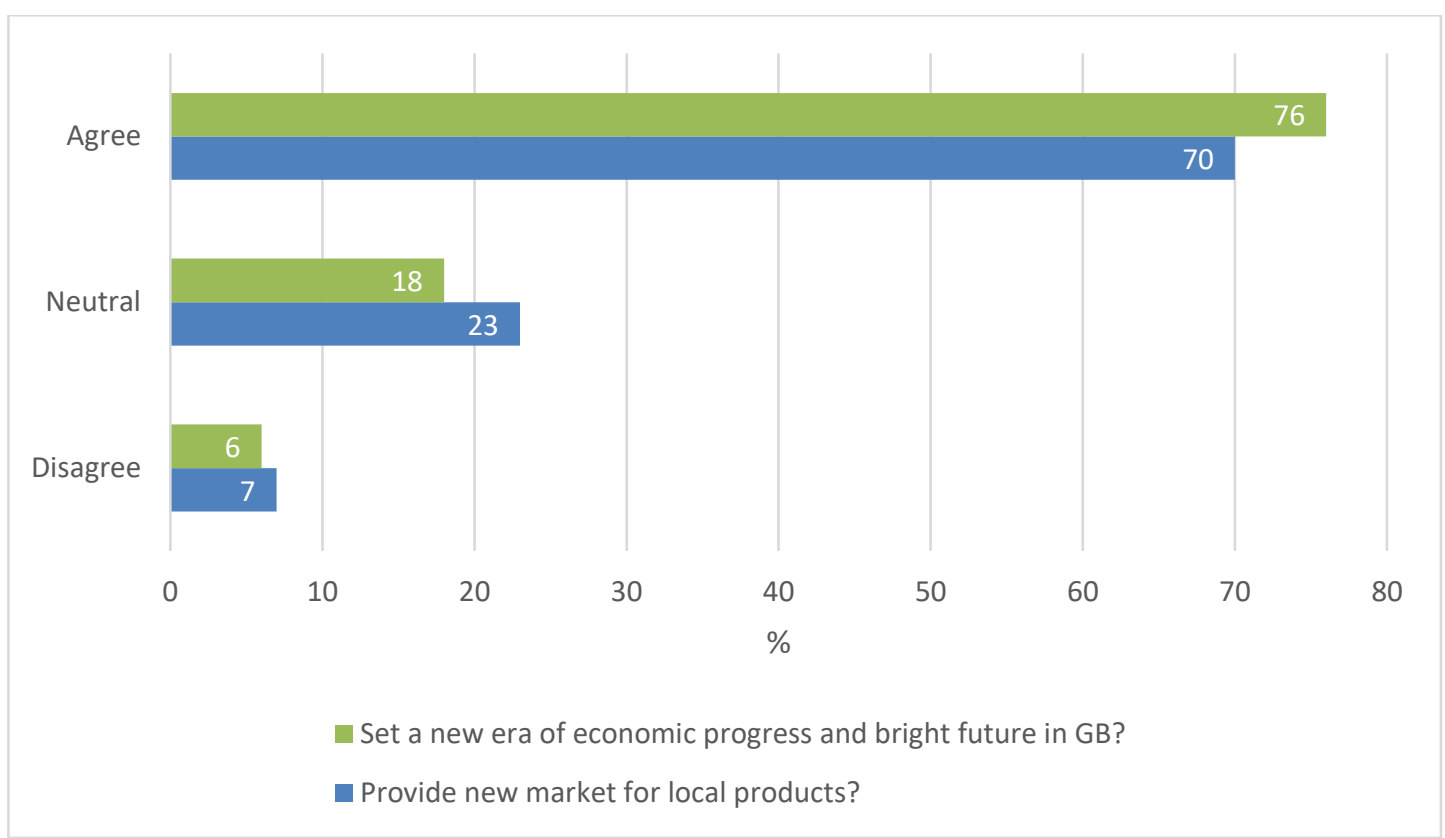

Figure 6: Economic Progress and Job Market under CPEC in Hunza Valley 


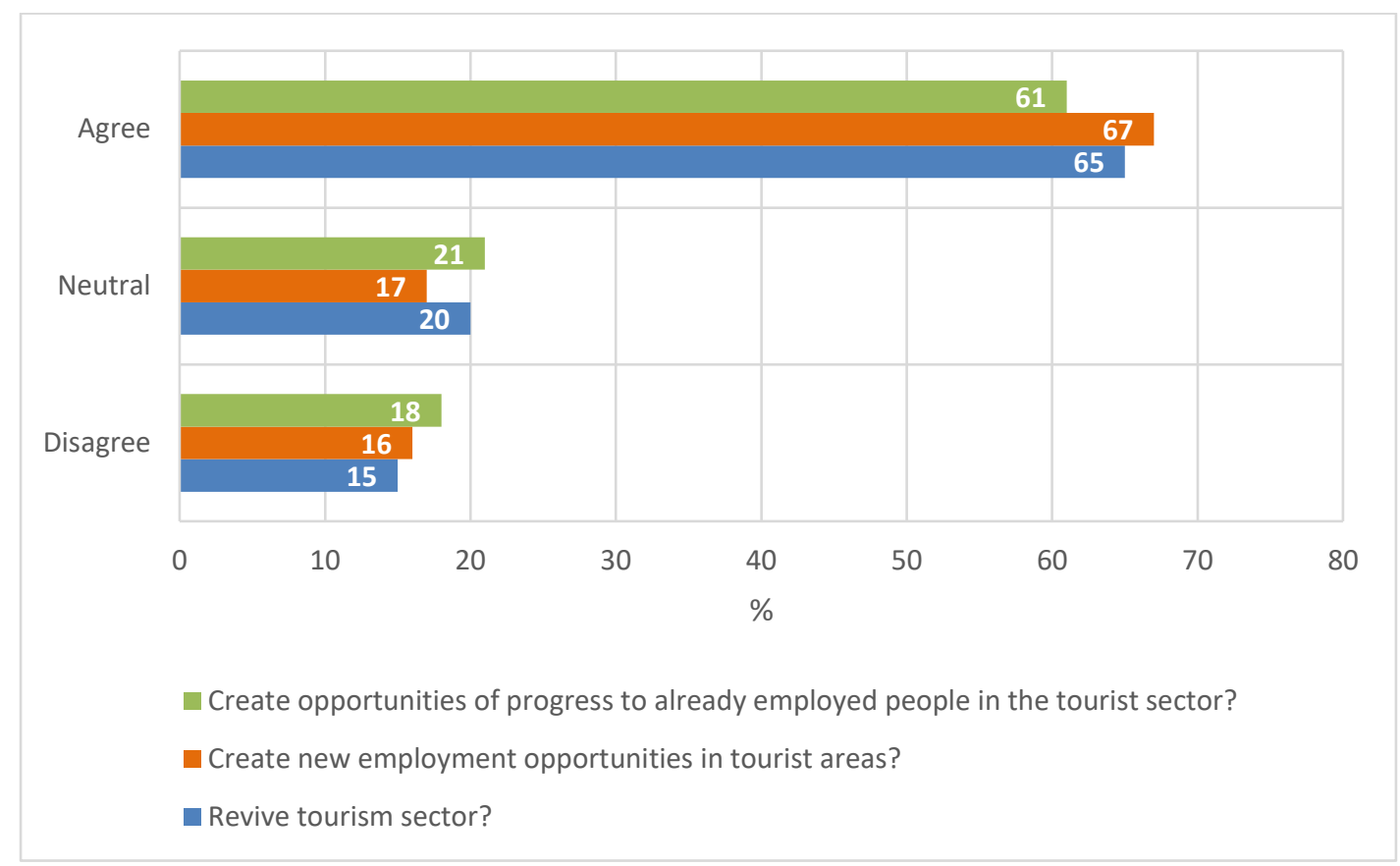

Figure 7: Tourism Industry under CPEC in Hunza Valley

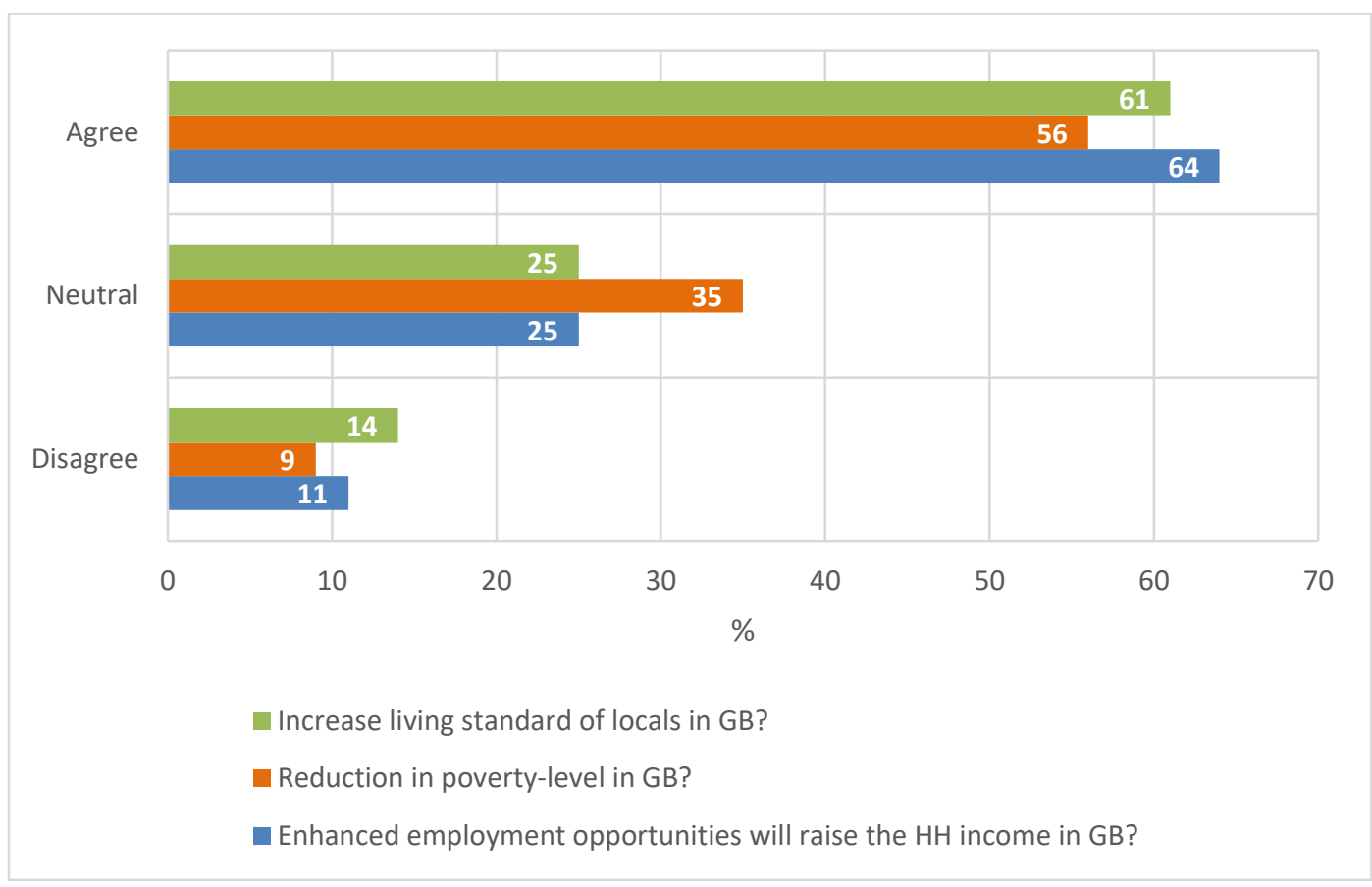

Figure 8: HH Income and Enhanced Living Standard under CPEC in Hunza V alley 


\section{Conclusion}

It is obvious that CPEC is the game-changer initiatives in the region of GilgitBaltistan particularly for those areas where CPEC route and other development activities will take place directly and immediately after the initiation of CPEC [Abid and Ashfaq (2015)]. Though CPEC will have its impact on all neighbouring countries, however Pakistan (after China) will be benefiting the most. Although CPEC will bring improvement in all spheres of life of the local people of GB, few sectors will improve more efficiently, these include communication (road links and internet), tourism industry including hoteling, small scale industries, energy sector, and business sector. It is derived from the research that $\mathrm{CPEC}$ is a great project for the people of GB; it will create employment opportunities for them through which they can improve their standard of living. $60 \%$ of the local respondents, $70 \%$ members of GBLA and $80 \%$ of the members of the Chamber of Commerce were hopeful that CPEC will create employment opportunities for the local community.

Due to high potential of GB in tourism sector, a high number of respondent $(53 \%)$ expected that tourism sector will develop through CPEC while $28 \%$ of the local people and the members of Chamber of Commerce expected that industrial sector will get boost through CPEC, 19\% of the respondents were having opinion that agriculture sector will develop through this mega project.

The myth that Gilgit-Baltistan, being an entry point of CPEC, will harvest the benefits of CPEC and it will improve both economic and social indicators [Shafique and Iftikhar (2017)], are cross-checked by this research that CPEC is a great project for the people of GB as it will create employment opportunities for them through and that will lead to enhance the standard of living of the local populace. But on the other side, many of the local people of GB seemed worried and fearful that this backward province will not get much benefit from this mega-investment [Mir (2016)]. The study further proves that CPEC will play a positive role in the expansion of jobs and markets, which will bring prosperity to the people, particularly among educated youth.

\section{Acknowledgment}

The authors are indebted to the journal editor and anonymous reviewers for their valuable time and critical remarks to refine the research findings that are finally presented in this paper.

\section{Declaration of Conflict of Interests}

The authors of this study and research affirm no conflict of interests, either with respect to the research and authorship, and/or submission of this research paper.

\section{References}

Abid, M., and A. Ashfaq. (2015) CPEC: Challenges and opportunities for Pakistan. Journal of Pakistan Vision, $16: 2,142-169$.

Anand, B.V. (2015) The impact of China' "One Belt, One Road" strategy on political, military and economic situations in the Asia Pacific region. Vivekananda International Foundation, India. 
Azeemi, H.R. (2007) 55 Years of Pakistan-China Relationship. Pakistan Institute of International Affairs. Pakistan Horizon, 60:2, 109-124, Pakistan's foreign policy analysis.

Bansal, A. (2007) In Pursuit of Forced Assimilation: Sectarian and Ethnic Marginalization in Gilgit-Baltistan. India Quarterly, 63:2, 56-80.

Bar-On, R., D.Tranel., N.L.Denburg, \& A. Bechara (2004). Emotional and social intelligence. Social neuroscience: key readings, 223, 52.

Black, W.R. (1996) Sustainable transportation: a US perspective. Journal of transport geography, 4:3, 151-159.

Butt, K.M., and A.A. Butt (2015) Impact of CPEC on Regional and Extra-Regional Actors. The Journal of Political Science, 33:1, 23.

Corning, P. A. (1982). Durkheim and Spencer. British Journal of Sociology, 359-382.

Dinar, H., W. Chaudhry, A.G. Chaudhry and M. Zeeshan (2015). Transformation and Retention: A Case Study of Hunzukutz in Islamabad. Science International Labore, 27:1, 741-743.

Hamid, N., and S. Hayat (2012) The opportunities and pitfalls of Pakistan's Trade with China and Other Neighbors. The Lahore Journal of Economics, 5:23, 271-292.

Hauptfleisch, A.C., and H.J. Marx (2011) The Potential Impact on Property and Socio-Economic Development Resulting from Road Transport Corridors in Africa: A case study.

Hussain, A., D.Fisher and S. Espiner (2017) Transport infrastructure and social inclusion: A case study of tourism in the region of Gilgit-Baltistan. Social Inclusion, 5:4, 196-208.

Ibrar, M., J. Mi, M. Rafiq and A.L Karn (2016) The China-Pakistan Economic Corridor: Security Challenges. DEStech Transactions on Economics, Business and Management.

Jeremy G., and G. Nezih (2008) Social change. Discussion Paper No. 3485

Johnson, C. K. (2016) President Xi Jinping's 'Belt and Road Initiative'. Center for Strategic and International Studies, United States.

Khan, I., S. Farooq., \& S. Gul (2016). China-Pakistan Economic Corridor: News Discourse Analysis of Indian Print Media. Journal of Political Studies, 23(1), 233.

Khan, S.A. (2013) Geo-Economic Imperatives of Gwadar Sea Port and Kashgar Economic Zone for Pakistan and China. IPRI Journal, 13:2, 87-100.

Lewin, K. (1947). Group decision and social change. Readings in social psychology, 3(1), 197-211.

Litman, T. (2002) Evaluating transportation equity. World Transport Policy and Practice, 8:2, 50-65.

Malik, S., \& S.Kumar. (2012). Management of hotel waste: a case study of small hotels of Haryana state. Journal of Economics and Management, 1(9), 2278-0629.

Mateu-Sbert, J., I. Ricci-Cabello, E. Villalonga-Olives, and E. Cabeza-Irigoyen (2013) The impact of tourism on municipal solid waste generation: The Case of Menorca Island (Spain). Waste Management, 33:12, 25892593.

Mbaiwa, J.E. (2003). The socio-economic and environmental impacts of tourism development on the Okavango Delta, north-western Botswana. Journal of arid environments, 54(2), 447-467.

Mir, S. (2016) Gilgit-Baltistan fears it will not benefit from CPEC. The Express Tribune. https://tribune.com.pk/story/1159747/

Mohmand, Y.T., A.Wang and A. Saeed (2017) The impact of transportation infrastructure on economic growth: empirical evidence from Pakistan. Transportation Letters, 9:2, 63-69.

Neelum, N. (2017) Establishing Special Economic Zone in Gilgit-Baltistan under CPEC. Institute of Strategic Studies.

Nogales, E. (2014) Making economic corridors work for the agricultural sector. FAO, Italy.

Peterson, C. (2013). Assessment of solid waste management practices and its vulnerability to climate risks in Maldives Tourism Sector. Report submitted to Ministry of Tourism, Arts and Culture.

Quijano, A. (2007). Coloniality and modernity/rationality. Cultural studies, 21(2-3), 168-178.

Rana, A. (2016) Pak-China Economic Corridor and Prospects of Tourism Revival. The Diplomatic Insight, 9:2.

Rogerson, C.M. (2001) Spatial development initiatives in Southern Africa: the Maputo development corridor. Tijdschrift voor economische en sociale geografie, 92:3, 324-346.

Rogerson, C.M. (2002) Tourism and local economic development: the case of the Highlands Meander. Development Southern Africa, 19:1, 143-167.

Saeed, A. (2016) The evolving Pakistan- China maritime economic relationship in the Indian ocean. Soundings, Sea Power Centre, Australia.

Sering, S.H. (2010) Constitutional Impasse in Gilgit-Baltistan (Jammu and Kashmir): The Fallout. 354-358.

Shafique, M., and G.A. Iftikhar (2017) Regional Dynamics of China Pakistan Economic Corridor (CPEC): The Case of Gilgit Baltistan. Journal of Historical Studies, 3:2, 15-29. 
Shaikh, F., Q. Ji, and Y. Fan (2016) Prospects of Pakistan-China energy and economic corridor. Renewable and Sustainable Energy Reviews, 59:0, 253-263.

Sial, S. (2014) The China-Pakistan Economic Corridor: an assessment of potential threats and constraints. Conflict and Peace Studies, 6:2, 24.

Taaffe, E.J., R. L. Morrill and P.R. Gould (1963) Transport expansion in underdeveloped countries: a comparative analysis. Geographical Review, 53:4, 503-529.

Thomas, R.H. (2009) Development corridors and spatial development initiatives in Africa. 3:2, World Bank, United States.

Trimble, J. E. (2003). Introduction: Social change and acculturation. Acculturation: Advances in theory, measurement, and applied research, 10, 3-13.

Wolf, S.O. (2016) The China-Pakistan Economic Corridor: An Assessment of its Feasibility and Impact on Regional Cooperation. Social Science Research Network. United States.

The Express Tribune. (2018). CPEC will improve tourism services in the country. https://tribune.com.pk/story/1600802/2-cpec-will-improve-tourism-servicescountry/

Ashraf, M.M. (2017). The CPEC opportunity. DAWN News (bttps://aurora.dawn.com/ news/1141730) 